\title{
A New Fe (III)-Selective Membrane Electrode Based on Fe (II) Phthalocyanine
}

\author{
Tugba Ozer and Ibrahim Isildak* \\ Faculty of Chemistry-Metallurgy, Department of Bioengineering, Yildiz Technical University, 34220, Istanbul, Turkey
}

\begin{abstract}
A new miniaturized all solid-state contact Fe (III)-selective PVC membrane electrode based on Fe (II) phthalocyanine as a neutral carrier was described. The effects of the membrane composition and foreign ions on the electrode performance was investigated. The best performance was obtained with a membrane containing $32 \%$ poly (vinyl chloride), $64 \%$ dioctylsebacate, $3 \%$ Fe (II) phthalocyanine, and 1\% potassium tetrakis (p-chlorophenyl) borate. The electrode showed near Nernstian response of $26.04 \pm 0.95 \mathrm{mV} /$ decade over the wide linear concentration range $1.0 \times 10^{-6}$ to $1.0 \times 10^{-1} \mathrm{M}$, and a very low limit of detection $1.8 \pm 0.5 \times 10^{-7} \mathrm{M}$. The potentiometric response of the developed electrode was independent at $\mathrm{pH}$ 3.5-5.7. The lifetime of the electrode was approximately 3 months and the response time was very short $(<7 \mathrm{~s})$. It exhibited excellent selectivity towards Fe (III) over various cations. The miniaturized all solid-state contact Fe (III)-selective membrane electrode was successfully applied as an indicator electrode for the potentiometric titration of $1.0 \times 10^{-3} \mathrm{M} \mathrm{Fe}$ (III) ions with a $1.0 \times 10^{-2} \mathrm{M}$ EDTA and the direct determination of Fe (III) ions in real water samples.
\end{abstract}

Keywords : PVC Membrane, Ion Selective Electrode, Fe (III), Phthalocyanine

Received : 31 March 2019, Accepted : 3 May 2019

\section{Introduction}

Iron, which is the fourth most abundant element in the earth's crust, is essential for the cellular processes including electron transfer, the transportation of oxygen, transcriptional regulation $[1,2]$. Also, iron is a limiting nutrient for phytoplankton in southern oceans, and has important role in photosynthetic and respiratory electron transport, chlorophyll synthesis, and nitrate reduction $[3,4]$. Moreover, Fe (III) is present in various enzymes such as catalase, cytochrome $\mathrm{C}$, aldolase, and takes place in the central nervous system as a cofactor. Since iron deficiency and accumulation in the body can result in various disorders such as Parkinson's, Huntington's, and Alzheimer's disease, hepatitis, hemochromatosis, cancer, heart disease, and diabetes, the concentration of iron in human body should be monitored [5-8]. Iron is a moderately toxic element among other transition

*E-mail address: iisildak@gmail.com

DOI: https://doi.org/10.33961/jecst.2019.00038

This is an open-access article distributed under the terms of the Creative Commons Attribution Non-Commercial License (http://creativecommons.org/licenses/by-nc/4.0) which permits unrestricted non-commercial use, distribution, and reproduction in any medium, provided the original work is properly cited. metals and may enter into watersheds as pollutant due to its numerous industrial applications in steel, water pipes, paints, plastic, and medical industry. Therefore, the quantitative detection of Fe (III) ions in clinical, biological and environmental samples has become important.

It has been reported that several analytical techniques such as chemiluminescence [9, 10], fluorescence [11], spectrometry [12], electrothermal atomic absorption spectrometry [13], inductively coupled plasma spectrometry [14], and inductively coupled optical emission spectrometry [15] have been deployed to determine aqueous iron concentration. Although these techniques provide accurate results, they are not suitable for routine and on-site analysis. Since they require sample pretreatments, sophisticated and expensive instruments, they are time-consuming and labor-intensive [16].

Phthalocyanines which is a $\pi$-conjugated metallomacrocycles have many applications in modern science and technology such as sensors, oxidation catalysts and photocatalysis $[17,18]$. Metallophthalocyanines (MPc), 2-dimensional 18-electron aromatic porphyrin synthetic analogues with an electroactive 
metal center which is capable of binding transition heavy metals and are employed as electrical devices, solar cells and biosensors due to their superior electronic properties [19]. It has been showed that electroactive metals such as cobalt $(\mathrm{Co})$ and iron $(\mathrm{Fe})$ enhance the catalytic performance of MPcs towards heavy metal detection [20]. The studies about the phthalocyanines, including derivatives of $\mathrm{Ag}, \mathrm{Co}, \mathrm{Cr}$, $\mathrm{Fe}, \mathrm{Mn}, \mathrm{Re}, \mathrm{Ru}$, etc., for which both the metal center and the macrocycle exhibited redox properties at electrodes [21].

A polymer matrix consisting of polyvinyl chloride plasticized with DOS or o-NPOE has been utilized for the fabrication of ion selective membranes since it has high hydrophobicity and good physical and mechanical properties to form thin membranes [22]. An ion selective membrane includes a hydrophobic ionophore and a hydrophobic ion exchanger which are dissolved in the polymer matrix. When the sample solution interact with the membrane, primary ions are carried to the membrane phase by forming a complex with the ionophore inside the membrane. The membrane potential which is generated by this interaction at the membrane interface can be measured against reference electrodes [23].

All solid-state contact ion selective electrodes (ISEs) are sensitive, miniaturized, rapid, low-cost, and portable devices allowing on-site measurements. In this study, $\mathrm{Fe}$ (II) phthalocyanine was used for fabrication an all solid-state contact Fe (III)-selective electrode for the first time. The fabricated electrode was successfully applied for the determination of Fe (III) ions in different water samples.

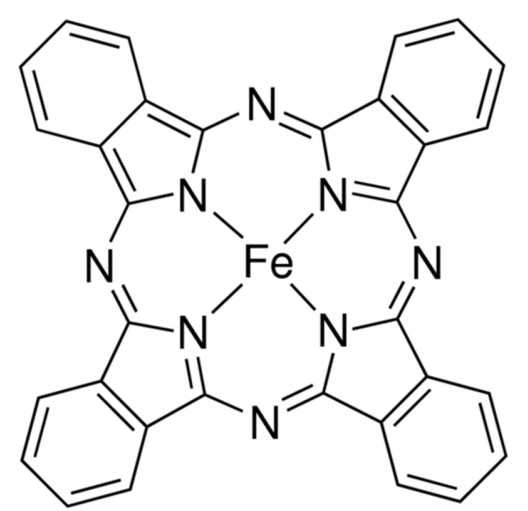

Fig. 1. The chemical structure of Fe (II) phthalocyanine

\section{Experimental}

\subsection{Chemicals and reagents}

All chemicals and reagents were of analytical grade quality and were used as received. Tetrahydrofuran (THF), potassium tetrakis ( $\mathrm{p}$-chlorophenyl) borate (KTpClPB), graphite, Fe (II) phthalocyanine, high molecular weight poly(vinyl chloride) (PVC) and plasticizers, o-nitrophenyl octyl ether (NPOE), dioctylsebacate (DOS), dibutyl phthalate (DBP), dioctyl phthalate (DOP) were purchased from Fluka (Bucks, Switzerland). Epoxy (Macroplast Su 2227) and hardener (Desmodur RFE) were obtained from Henkel (Istanbul, Turkey) and Bayer AG (Darmstadt, Germany) respectively. All of the cationic solutions were prepared from their nitrate and chloride salt in doubly distilled water and, used without any further purification except for vacuum drying over $\mathrm{P}_{2} \mathrm{O}_{5}$. Fe (III) chloride hexahydrate $\left(\mathrm{FeCl}_{3} \cdot 6 \mathrm{H}_{2} \mathrm{O},>99.5 \%\right)$ was purchased from Merck. Ultrapure water $\left(\sim 18.2 \mathrm{M} \Omega \cdot \mathrm{cm}, 25^{\circ} \mathrm{C}\right)$ was acquired using the Water Purifying System. A stock solution of Fe (III) ion was prepared daily while working solutions were prepared with appropriate dilutions of the stock solution immediately before use. Other metal ion solutions were prepared from $1 \mathrm{M}$ stock solutions after suitable dilutions.

\subsection{Apparatus}

The potentiometric measurements was performed by using a computer-controlled high-input impedance multi-channel potentiometric measurement system (sensitivity $\pm 0.1 \mathrm{mV}$ ) with a custom-made software program (Medisen Ar-Ge, Turkey). All electrode potentials were measured against an $\mathrm{Ag}$ / $\mathrm{AgCl} \mathrm{KCl}$ (saturated) reference electrode (RE) (MF2052 model, BASi). HI9126 (Hanna Instruments) waterproof portable $\mathrm{pH} / \mathrm{mV}$ meter including the HI1230B double junction $\mathrm{pH}$ electrode was used to control the $\mathrm{pH}$ value of the solutions. The $\mathrm{pH}$ electrode was calibrated by using $\mathrm{pH}$ standard buffer solutions (Hanna Instruments) for $\mathrm{pH} \mathrm{4,} 7$ and 10 before each experiment. Branson ultrasonic bath was used to homogenize solutions at their essential concentrations. Dissolved oxygen (DO) was measured using an Oakton DO 300 Series field meter; temperature, $\mathrm{pH}$, and oxidation-reduction potential (ORP) were measured with Beckman U265 pH/Temp/mV meters; and an Oakton CON 400 series field meter 


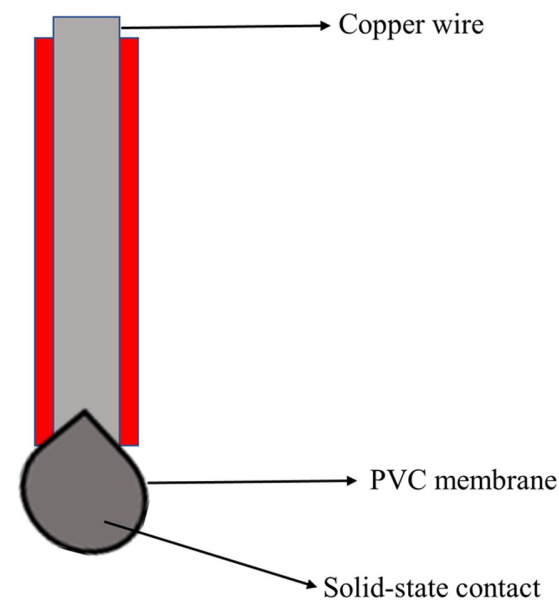

Fig. 2. Schematic illustration of the all solid-state contact electrode.

was used to measure conductivity. Inductively coupled plasma optical emission spectrometry (Optima 7300DV ICP-OES, Perkin Elmer, USA) was applied for analysis of environmental samples.

All glassware were cleaned by soaking overnight into a $3 \mathrm{M}$ nitric acid solution. Then, they were further washed with tap water and deionized water. The glassware was then dried in an oven at $100^{\circ} \mathrm{C}$ for $1 \mathrm{~h}$, cooled at room temperature and used for experimental work.

\subsection{Preparation of the electrode}

Details on the fabrication of micro-sized PVC membrane based electrode have been previously published [24]. A mixture of 32\% PVC, 64\% DOS, $3 \% \mathrm{Fe}$ (II) phthalocyanine, and $1 \% \mathrm{KTpCIPB}$ was dissolved in $5 \mathrm{~mL}$ THF. Then, this mixture was shaken. The solution was evaporated slowly until an oily concentrated solution was attained. After that, all solid-state contact electrode previously prepared was dipped into the concentrated membrane solution to obtain a transparent membrane film. The electrode membranes were allowed to dry overnight in the air and conditioned for $12 \mathrm{~h}$ in a $1.0 \times 10^{-2} \mathrm{M} \mathrm{FeCl}_{3} \cdot 6 \mathrm{H}_{2} \mathrm{O}$ solution.

\subsection{Emf measurements}

Potential difference between ISE and reference electrode was proportional to the logarithm of the ion activity based on Nernst-equation. The potential response values of the Fe (III) ion-selective mem- brane electrode were measured at steady-state for different concentration of standard solutions of Fe (III) ions respectively. All potentiometric measurements with the all solid-state contact PVC membrane electrode were carried out under zero-current flow and at $25^{\circ} \mathrm{C}$ with cell of the type: Micro-sized $\mathrm{Ag} / \mathrm{AgCl} \mathrm{RE}$ Test solution | PVC membrane $\mid \mathrm{Cu}$ wire surface.

$\mathrm{An} \mathrm{Ag} / \mathrm{AgCl}$ chloride reference electrode including a saturated solution of $\mathrm{KCl}$ was used throughout the emf measurements. Adequate increments of $\mathrm{Fe}$ (III) solution were added to $20 \mathrm{~mL}$ of $2 \times 10^{-2} \mathrm{M}$ acetate buffer solution ( $\mathrm{pH} 4.0$ ) to obtain the concentration range of $1.0 \times 10^{-6}$ to $1.0 \times 10^{-1} \mathrm{M}$ following by recording emf values after each addition. Then, calibration graphs were plotted by using the recorded potentials versus $\log$ [Fe (III) ion]. The obtained graphs were evaluated in order to identify the response of the proposed electrode.

\subsection{Assay of real waters for Fe (III) ion detection}

After $10 \mathrm{~mL}$ of water samples were transferred to a $25 \mathrm{~mL}$ beaker, the $\mathrm{pH}$ of samples was adjusted to 4 by adding small amount of concentrated nitric acid. Potentiometric calibration of Fe (III) ion-selective electrode was used in order to determine Fe (III) ion content in water samples. The results were validated by analyzing of Fe (III) ions in the samples using ICP-MS to ensure the accuracy of the developed electrode.

\section{Results and Discussion}

All solid-state contact PVC membrane Fe (III)selective electrodes were constructed in order to determine the suitability of ionophore in PVC membrane for various cations. After the electrodes were conditioned by soaking into the nitrate or chloride solution of each cation, the potentiometric responses of the electrodes were measured toward different cations. As shown in Fig. 3, the slopes of the corresponding potential versus $\mathrm{p}\left[\mathrm{M}^{\mathrm{n}+}\right]$ plots were much lower than the expected Nernstian slopes except for $\mathrm{Fe}$ (III) ion. It was observed that the all solid-state contact PVC membrane electrode could be used for sensitive detection of $\mathrm{Fe}$ (III) ion over a wide concentration range due to higher affinity of $\mathrm{Fe}$ (II) phthalocyanine to trivalent iron ion over other ions. Thus, the $\mathrm{Fe}$ (II) phthalocyanine was chosen as ionophore for fabricating $\mathrm{Fe}$ (III) ion-selective membrane, and the 
response characteristics of the developed all solidstate contact membrane electrode were investigated in further studies.

\subsection{Optimization of membrane components}

The membrane composition, the properties of plasticizers and additive used have impact on the sensitivity, selectivity and linearity of the potentiometric electrodes $[25,26]$. The plasticizers enhance the working concentration range, stability and life time of the electrode due to their nature $[27,28,29]$. Therefore, the effect of different membrane compositions as well as the nature and amount of the plasticizer (DOS, DBP, NPOE and DOP) on the response characteristics of the constructed Fe (III)-ion-selective electrode were analyzed (Table 1). It is obvious from Table 1 that the electrode displayed a very limited slope and linear range for lack of ionophore (no 6). After the ionophore was added, the linear range and slope of the electrode response were elevated. The results showed that the membrane containing DOS as plasticizer had the best sensitivity and linear range

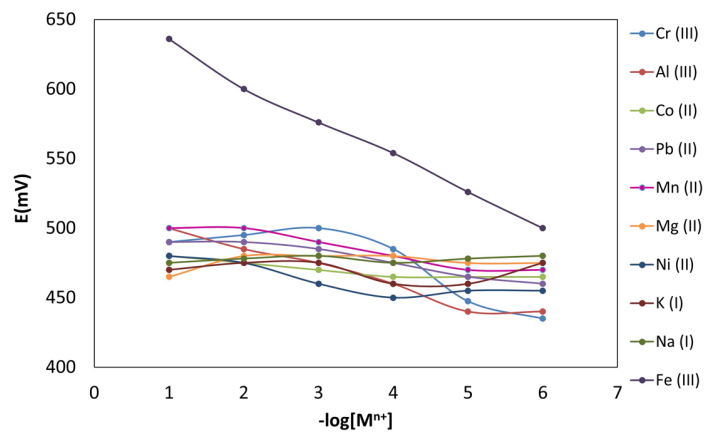

Fig. 3. The potential response of all solid-state contact PVC membrane Fe (III)-selective electrode against Fe (III) ion and some potential interferent ions. among four different plasticizers (no 1). Moreover, a plasticizer/PVC ratio of 2 was used as the optimum amount in the PVC membrane [30]. KTpCIPB was used as an ionic additive in the membrane composition of the electrode. As can be seen in Table 1, the developed electrode did not exhibit Nernstian response characteristics (no. 5) in the absence of additive. The response behavior of the electrode can be enhanced because the presence of lipophilic additives in the membrane composition reduces the ohmic resistance [31]. The optimum amount of KTpClPB was found to be $1 \mathrm{mg}$ since additive improved the slope of the calibration curve to a near Nernstian slope of $26.04 \mathrm{mV} /$ decade over a wide concentration range (no. 1). Thus, the membrane composition consisting of $32 \%$ PVC, $64 \%$ DOS, 3\% ionophore, $1 \%$ $\mathrm{KTpCIPB}$ was selected as the membrane composition for the best potentiometric response of the electrode (Table 1, no 1).

\subsection{The calibration curve, detection limit, and reproducibility of the $\mathrm{Fe}$ (III)-selective electrode}

The Fe (III)-selective membrane electrode was conditioned by soaking into a $1 \times 10^{-2} \mathrm{M} \mathrm{Fe}$ (III) ion solution for $12 \mathrm{~h}$ to assure the equilibrium at the membrane-water interface. Stable potentials were acquired when the conditioned electrodes were placed into Fe (III) ion solutions. A calibration curve (Fig. 4) for the optimized membrane electrode towards different $\mathrm{Fe}$ (III) ion concentrations was obtained. The limit of detection (LOD) was determined as $1.8 \pm 0.5 \times 10^{-7} \mathrm{M}$ for Fe (III) ion according to IUPAC recommendations by crossing of two extrapolated segments of the calibration curve [32].

Four different electrodes with the same optimized compositions were used in order to examine the reproducibility of the proposed electrode. The rela-

Table 1. Composition and response characteristics of Fe (III) ion-selective electrode.

\begin{tabular}{|c|c|c|c|c|c|c|}
\hline \multirow[b]{2}{*}{ S. no. } & \multicolumn{4}{|c|}{ Composition of the membrane $\%(w / w)$} & \multirow{2}{*}{ Linear range $(\mathrm{M})$} & \multirow{2}{*}{ Slope (mV/decade) } \\
\hline & $\mathrm{PVC}$ & Plasticizer & KTрCIPB & Ionophore & & \\
\hline 1 & 32 & 64 (DOS) & 1 & 3 & $1.0 \times 10^{-1}$ to $1.0 \times 10^{-6}$ & 26.04 \\
\hline 2 & 32 & 64 (DBP) & 1 & 3 & $1.0 \times 10^{-3}$ to $1.0 \times 10^{-5}$ & 12.9 \\
\hline 3 & 32 & 64 (DOP) & 1 & 3 & $1.0 \times 10^{-3}$ to $1.0 \times 10^{-5}$ & 9.5 \\
\hline 4 & 32 & 64 (NPOE) & 1 & 3 & $1.0 \times 10^{-3}$ to $1.0 \times 10^{-5}$ & 29.80 \\
\hline 5 & 32 & 64 (DOS) & 0 & 4 & - & - \\
\hline 6 & 33 & 66 (DOS) & 1 & 0 & $1.0 \times 10^{-3}$ to $1.0 \times 10^{-5}$ & 10.1 \\
\hline
\end{tabular}




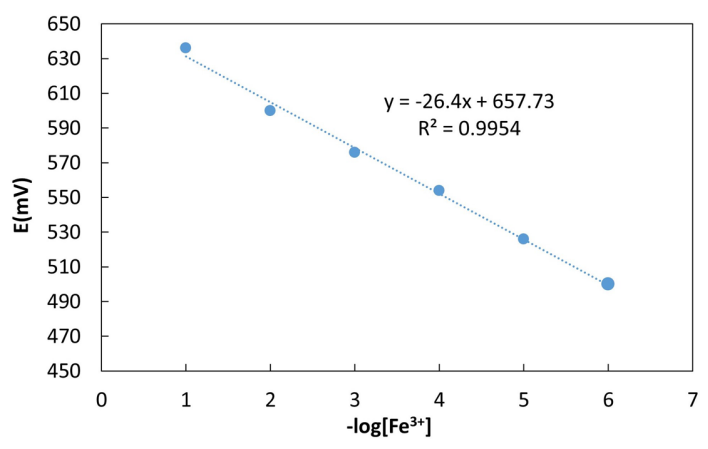

Fig. 4. Calibration curve of all solid-state contact PVC membrane Fe (III) ion-selective electrode.

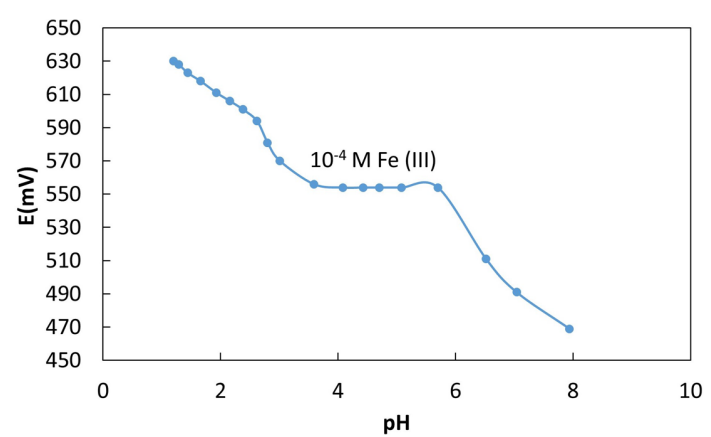

Fig. 5. Effect of $\mathrm{pH}$ on the potential response of the electrode in the presence of $1 \times 10^{-4} \mathrm{M}$ of $\mathrm{Fe}$ (III) ions.

tive standard deviation (RSD) for five measurements was attained as $3.1 \%$. The repeatability of the electrode was also determined by five measurements with one electrode and the calculated RSD was $3.6 \%$.

\subsection{Effect of pH}

The effect of $\mathrm{pH}$ on the potential response of the electrode was observed by adding suitable amount of $\mathrm{HNO}_{3}$ and $\mathrm{NaOH}$ to $1.0 \times 10^{-4} \mathrm{M} \mathrm{Fe}$ (III) ion solution over the $\mathrm{pH}$ range of 1.0-8.0. The potentials remained constant in the $\mathrm{pH}$ range of 3.5-5.7 (Fig. 5). Some hydroxyl complexes of $\mathrm{Fe}$ (III) ions could form at higher $\mathrm{pH}$ values $(\mathrm{pH}>5.7)$ while resulting in the potential drift due to the reduced the free Fe (III) ion in the solution $[33,24]$. It was observed that the potentials increased at lower $\mathrm{pH}$ values because the membrane electrode may give response to hydrogen ions. Afterwards, the real sample $\mathrm{pH}$ values were adjusted at 4.0 by acetate buffer solution during $\mathrm{Fe}$ (III) ion determination.

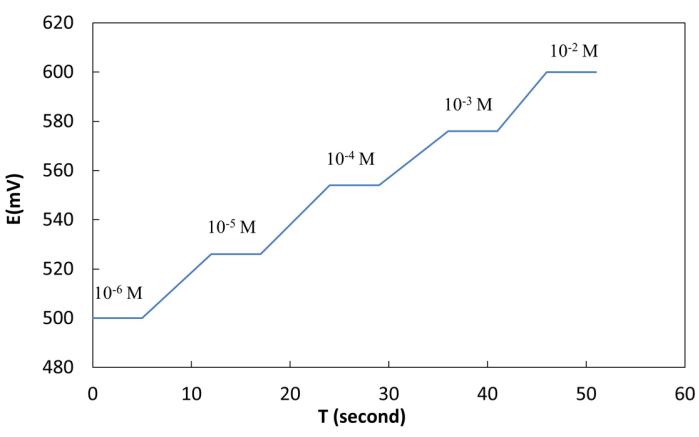

Fig. 6. Dynamic response time of the suggested electrode for step changes in the different concentration of Fe (III) ions.

\subsection{Dynamic response time and lifetime of the electrode}

Dynamic response time of the electrode was observed by measuring the average time required to achieve a $95 \%$ value of steady potential after the electrode was employed the diverse concentration of $\mathrm{Fe}$ (III) ion solution from lower $\left(1.0 \times 10^{-4} \mathrm{M}\right)$ to higher $\left(1.0 \times 10^{-2} \mathrm{M}\right)$. The attained results (Fig. 6) exhibit that the average response time for this Fe (III) ion-selective electrode is less than $7 \mathrm{~s}$.

The potentiometric responses of the electrode in $\mathrm{pH} 4$ were recorded over a period of 12 weeks to investigate the lifetime of the electrode. The electrode could be used without any significant divergence during this time. However, after 12 weeks small changes were observed in the slope (from 26.04 to $22.10 \mathrm{mV} \mathrm{decade}^{-1}$ ). The lifetime of a polymeric membrane electrode in potentiometric measurements is confined due to the leakage of the membrane ingredients especially the ionophore into the working solutions.

\subsection{Interference study}

Selective detection of Fe (III), regarding to the ionophore used, might be attained from interactions between Fe (II)/ Fe (III) phthalocyanine complexes. $\mathrm{Fe}$ (II)-phthalocyanine is a four coordinated complex with a square planner structure. The Fe (II) centers are soft and it is capable for efficient and selective binding of soft $\mathrm{Fe}$ (III) ions [34]. Consequently, initial oxidation of the $\mathrm{Fe}$ (II) to $\mathrm{Fe}$ (III) followed in terms of an enhanced potential density that was observed when Fe (III) concentration increased. Different possible interfering species were evaluated for 
Table 2. Selectivity coefficients of various ions (B) for the fabricated electrode.

\begin{tabular}{cc}
\hline \hline interfering ions $(\mathrm{j})$ & $\log K_{\mathrm{Fe}(I I I), B}^{\text {Pot }}$ \\
\hline $\mathrm{Cr}^{3+}$ & -3.5 \\
$\mathrm{Al}^{3+}$ & -3.2 \\
$\mathrm{Co}^{2+}$ & -5.1 \\
$\mathrm{~Pb}^{2+}$ & -5.3 \\
$\mathrm{Cu}^{2+}$ & -5.2 \\
$\mathrm{Mg}^{2+}$ & -5.5 \\
$\mathrm{Mn}^{2+}$ & -4.5 \\
$\mathrm{Ni}^{2+}$ & -4.5 \\
$\mathrm{Zn}^{2+}$ & -4.6 \\
$\mathrm{Fe}^{2+}$ & -4.1 \\
$\mathrm{Na}^{+}$ & -6.0 \\
$\mathrm{~K}^{+}$ & -5.8 \\
\hline
\end{tabular}

their possible effects on the detection of Fe (III) ions. The match potential method (MPM) recommended by IUPAC [35] was applied in order to assess selectivity behavior of the proposed electrode. A certain concentration of $\mathrm{Fe}$ (III) solution was added to a reference solution $\left(1.0 \times 10^{-4} \mathrm{M}\right)$ and its potential was measured. After that, other cations solution was added to an identical reference solution until the attained potential response matched with the one obtained before adding Fe (III) ion. Then, the selectivity coefficient was calculated by the ratio of $\Delta \alpha_{A}$ (primary ion activity changes) to the $\alpha_{B}$ (interfering ion activity) which is expressed as:

$$
K_{F e(I I I), B}^{M P M}=\frac{\Delta a_{A}}{a_{B}}
$$

Thus, the selectivity coefficients should be determined to investigate the analytical usefulness of the electrode in order to determine the target ions in real samples. The acquired selectivity coefficients for the developed electrode are listed in Table 2 . The results show that the selectivity coefficients are of the order of $10^{-3.2}$ or smaller which indicate that the fabricated electrode exhibited a good selective response toward $\mathrm{Fe}$ (III) ions compared to the other ions.

\subsection{Analytical applications}

The constructed electrodes were used for the deter-

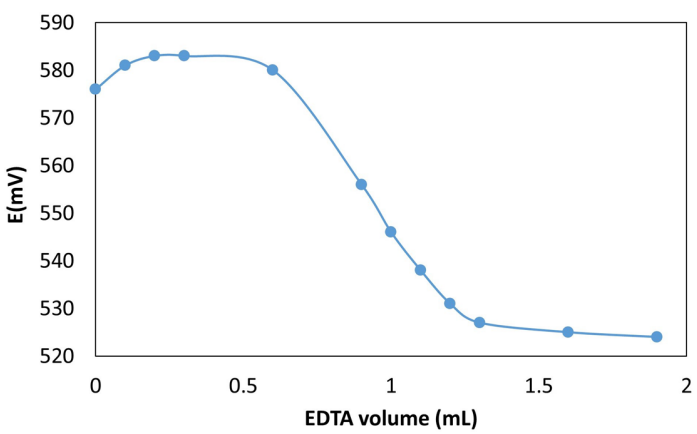

Fig. 7. Potentiometric titration of $10 \mathrm{~mL}$ of $\mathrm{Fe}$ (III) $\left(1 \times 10^{-3} \mathrm{M}\right)$ with EDTA $\left(1 \times 10^{-2} \mathrm{M}\right)$.

mination of $\mathrm{Fe}$ (III) ion concentration in tap water, mineral water and river water samples with using standard addition method as shown in (Table 3). The samples were prepared for analysis as mentioned in Section 2. The results obtained were also compared with those from ICP-OES analysis. It is obvious from the values in (Table 3 ) that there were a good agreement with those obtained by proposed electrodes and reported method. Hence, the electrodes can be successfully employed for the assessment of Fe (III) ions.

3.6.1. Potentiometric titration of Fe (III) using the developed electrode

The analytical utility of the fabricated Fe (III) ionselective electrode was tested by employing it as an indicator electrode in the titration of $10 \mathrm{~mL} 1.0 \times 10^{-3}$ $\mathrm{M} \mathrm{Fe}$ (III) ion solution adjusted by acetate buffer in $\mathrm{pH} 4$ with $1.0 \times 10^{-2} \mathrm{M}$ ethylenediaminetetraacetic acid (EDTA) solution. The resulting titration curve was shown in Fig. 7. As can be seen from Fig. 7, the potential values were reduced by adding EDTA to the solution due to forming complexation between $\mathrm{Fe}$ (III) ions with EDTA. Due to a 1:1 stoichiometry of the EDTA- Fe (III) ion complex, the potential response after the end point of the curve was constant. Thus, the developed electrode could be employed as an indicator electrode.

\subsubsection{Determination of Fe (III) in water samples}

The proposed electrode was applied to determine Fe (III) ion in tap water (Yildiz Technical University), mineral water (Kizilay mineral water, marketed in Turkey) and river water (Istanbul, Turkey) in order 
Table 3. Determination of $\mathrm{Fe}^{3+}$ content in some real samples.

\begin{tabular}{|c|c|c|c|c|}
\hline Samples & Added & The Value $\mathrm{mg} \mathrm{L}^{-1}$ (ISE Method) ${ }^{\mathrm{a}}$ & The Value $\mathrm{mg} \mathrm{L}^{-1}$ (ICP-OES) & Recovery, $\%$ \\
\hline \multirow[t]{2}{*}{ Tap water } & 0 & - & - & - \\
\hline & 20.0 & $20.5 \pm 0.4$ & $20.1 \pm 0.2$ & 101.9 \\
\hline \multirow[t]{2}{*}{ River water } & 0 & - & - & - \\
\hline & 30.0 & $30.8 \pm 0.5$ & $30.3 \pm 0.4$ & 101.6 \\
\hline \multirow[t]{2}{*}{ Mineral water } & 0 & - & - & - \\
\hline & 50.0 & $49.5 \pm 0.6$ & $50.4 \pm 0.7$ & 98.2 \\
\hline
\end{tabular}

${ }^{a}$ Average of six measurements

Table 4. Comparison study of the developed Fe (III) ion-selective electrode with other electrodes.

\begin{tabular}{|c|c|c|c|c|c|c|}
\hline No & Ionophore & Linear Range (M) & Detection limit (M) & Response time (s) & $\mathrm{pH}$ range & Ref. \\
\hline 1 & $\begin{array}{l}\text { 2-[(thiophen-2-yl)methyleneamino }] \text { iso- } \\
\text { indoline-1,3-dione }\end{array}$ & $1.0 \times 10^{-2}-1.0 \times 10^{-6}$ & $5.0 \times 10^{-7}$ & 10 & $2.3-4.8$ & [36] \\
\hline 2 & $\begin{array}{l}\text { 2-methyl-6 (4methylenecyclohex-2-en- } \\
\text { 1-yl)hept-2-en-4-one }\end{array}$ & $1.0 \times 10^{-2}-4.3 \times 10^{-7}$ & $4.3 \times 10^{-7}$ & 10 & $1.5-6.0$ & [37] \\
\hline 3 & $\begin{array}{c}\text { Phosphorylated Calix-6-Arene Deriva- } \\
\text { tive }\end{array}$ & $1.0 \times 10^{-2}-1.0 \times 10^{-4}$ & $1.0 \times 10^{-5}$ & 5 & $4.0-7.0$ & [38] \\
\hline 4 & $\begin{array}{l}\text { (E)-N'-((2-hydroxynaphthalen- } \\
\text { 3yl)methylene) benzohydrazide }\end{array}$ & $1.0 \times 10^{-2}-5.0 \times 10^{-9}$ & $1.0 \times 10^{-9}$ & 10 & $2.4-4.0$ & [39] \\
\hline 5 & norfloxacin & $1.0 \times 10^{-1}-1.0 \times 10^{-5}$ & $5.0 \times 10^{-6}$ & 10 & $3.0-8.0$ & [40] \\
\hline 6 & morin- $\mathrm{Fe}^{2+}$ schiff-base complex & $1.0 \times 10^{-1}-1.0 \times 10^{-6}$ & $4.5 \times 10^{-7}$ & $<10$ & $5.0-10.0$ & [24] \\
\hline This work & $\mathrm{Fe}$ (II) Phthalocyanines & $1.0 \times 10^{-1}-1.0 \times 10^{-6}$ & $1.8 \times 10^{-7}$ & $<7$ & $3.5-5.7$ & - \\
\hline
\end{tabular}

to investigate the applicability of the electrode. The $\mathrm{Fe}$ (III) concentrations in the samples were assessed by standard addition method.

\subsection{Comparison between the proposed and other published Fe (III) ion-selective electrodes}

The linear range, detection limit, response time and working $\mathrm{pH}$ range of the previous studies in detection of $\mathrm{Fe}$ (III) ions are compared with the proposed electrode in Table 4. Consequently, the novel all solidstate contact electrode for Fe (III) ion detection exhibits an excellent detection limit and wide linear dynamic range compared to previous works.

\section{Conclusions}

The all solid-state contact membrane Fe (III) ionselective electrode based on Fe (II) phthalocyanine was fabricated and investigated for sensitive and selective Fe (III) ion determination under acidic $\mathrm{pH}$ conditions. The suggested electrode presented the optimum sensitivity for $\mathrm{Fe}$ (III) ion over the range of $1.0 \times 10^{-6}$ to $1.0 \times 10^{-1} \mathrm{M}$ with a limit of detection $1.86 \pm 0.5 \times 10^{-7} \mathrm{M}$. The electrode exhibited a selective response in the presence of various interferents. In addition, Fe (III) ion in water samples was determined in order to investigate its real potential.

\section{Conflicts of Interest}

The authors declare no conflicts of interest.

\section{References}

[1] S. R. Taylor and S. M. McLennan, The Continental Crust: Its Composition and Evolution: An Examination of the Geochemical Record Preserved in Sedimentary Rocks, Blackwell Scientific, 1985.

[2] X. Liu and E. C Theil, Accounts Chem. Res., 2005, $38(3), 167-175$.

[3] J. G. Rueler and D. R. Ades, J. Phycol., 1987, 23(3), 452-457.

[4] P. Boyd and M. Ellwood, Nat. Geosci., 2010, 3(10), 675. 
[5] S. Oshiro, M. S. Morioka and M. Kikuchi, $A d v$. Pharmacol. Sci., 2011.

[6] D. J. Bonda, H. G. Lee, J. A. Blair, X. Zhu, G. Perry and M. A. Smith, Metallomics, 2011, 3(3), 267-270.

[7] D. Galaris, V. Skiada and A. Barbouti, Cancer Lett., 2008, 266(1), 21-29.

[8] S. K. Mittal, S. Rana, N. Kaur and C. E. Banks, Analyst, 2018, 143(12), 2851-2861.

[9] V. A. Elrod, K. S. Johnson and K. H. Coale, Anal. Chem., 1991, 63(9), 893-898.

[10] A. R. Bowie, E. P. Achterberg, R. F. C. Mantoura and P. J. Worsfold, Anal. Chim. Acta, 1998, 361(3), 189-200.

[11] K. W. Cha and K. W. Park, Talanta, 1998, 46(6), 15671571.

[12] M. Grotti, F. Soggia, F. Ardini and R. Frache, J. Anal. At. Spectrom., 2009, 24(4), 522-527.

[13] G. P. G. Freschi, C. D. Freschi and J. A. G. Neto, Microchim. Acta, 2008, 161(1-2), 129-135.

[14] J. De Jong, V. Schoemann, D. Lannuzel, J. L. Tison and N. Mattielli, Anal. Chim. Acta, 2008, 623(2), 126-139.

[15] Y. Cui, Z. J. Hu, J. X. Yang and H.W. Gao, Anal. Chim. Acta, 2012, 176(3-4), 359-366.

[16] N. A. Papadopoulou, A. B. Florou and M. I. Prodromidis, Anal. Lett., 2018, 51(1-2), 198-208.

[17] D. Akyüz, B. Keskin, U. Şahintürk and A. Koca, Appl. Catal. B, 2016, 188, 217-226.

[18] M. M. Ayhan, A. Singh, C. Hirel, A. G. Gu?rek, V. Ahsen, E. Jeanneau, I. Ledoux-Rak, J. Zyss, C. Andraud and Y. Bretonnière, J. Am. Chem. Soc., 2012, 134(8), 3655-3658.

[19] M. L. Rodriguez-Méndez, M. Gay and J. A. de Saja, $J$. Porphyr. Phthalocyanines, 2009, 13(11), 1159-1167.

[20] B. Çeken, M. Kandaz and A. Koca, Synth. Met., 2012, 162(17-18), 1524-1530.

[21] K. Kadish, K. M. Smith and R. Guilard, The Porphyrin Handbook, Academic Press, 2003.

[22] U. Khamjumphol, S. Watchasit, C. Suksai, W. Janrungroatsakul, S. Boonchiangma, T. Tuntulani and W. Ngeontae, Anal. Chim. Acta, 2011, 704(1-2), 73-86.

[23] E. Bakker, P. Bühlmann and E. Pretsch, Chem. Rev,
1997, 97(8), 3083-3132.

[24] T. Ozer and I. Isildak, Int. J. Electrochem. Sci., 2018, 13(12), 11375-11387.

[25] A. Malon, A. Radu, W. Qin, Y. Qin, A. Ceresa, M. MajZurawska, E. Bakker and E. Pretsch, Anal. Chem., 2003, 75(15), 3865-3871.

[26] A. Soleymanpour, B. Shafaatian, A. Hanifi and A. A. Jarrahpour, J. Electrochem. Soc., 2014, 161(1), 14-18.

[27] A. Soleymanpour, S. Abdifar and R. Bani, Electroanalysis, 2011, 23(12), 2813-2821.

[28] R. Eugster, T. Rosatzin, B. Rusterholz, B. Aebersold, U. Pedrazza, D. Rüegg, A. Schmid, U. E. Spichiger and W. Simon, Anal. Chim. Acta, 1994, 289(1), 1-13.

[29] T. A. Ali, A. A. Farag and G. G. Mohamed, J. Ind. Eng. Chem., 2014, 20(4), 2394-2400.

[30] F. J. Keplinger, A. Jachimowicz and F. Kohl, Anal. Chem., 1998, 70(20), 4271-4279.

[31] B. Shafaatian, S. O. Sadati, A. Soleymanpour and F. Amouzad, J. Anal. Chem., 2018, 73(12), 1202-1208.

[32] H. Ghohari, H. A. Zamani, F. Joz-Yarmohammadi, M. Ebrahimi and M. R. Abedi, Russ. J. Electrochem., 2018, 54(10), 747-754.

[33] F. Joz-Yarmohammadi, H. A. Zamani and F. Mohammadabadi, Int. J. Electrochem. Sci, 2015, 10, 8124-8136.

[34] M. Ghaedi, M. Montazerozohori, M. Behfar and F. Marahel, Int. J. Electrochem. Sci., 2011, 6, 6074-84.

[35] Y. Umezawa, K. Umezawa and H. Sato, Pure Appl. Chem., 1995, 67(3), 507-518.

[36] H. A. Zamani and F. Faridbod, J. Anal. Chem., 2014, 69(11), 1073-1078.

[37] T. A. Ali, G. G. Mohamed and A. H. Farag, Int. J. Electrochem. Sci, 2015, 10(1), 564-578.

[38] M. M. Zareh, W. Zordek and A. Abd-Alhady, J. Sens. Technol., 2014, 4(4), 186.

[39] A. Yari, M. Bagheri and M. A. Ghazizadeh, Int. J. Electrochem. Sci, 2016, 11, 6597-6608.

[40] A. L. Saber, A. M. Hameed, A. A. Sayqal, H. Alessa and A. Alharbi, Int. J. Electrochem. Sci., 2018, 13, 10076-10087. 